\title{
VESTUÁRIO DE ALUNAS DE UMA ESCOLA DE ENFERMAGEM BRASILEIRA: RELAÇÕES COM A IDENTIDADE PROFISSIONAL (1947-1965)
}

\author{
STUDENT UNIFORMS IN A BRAZILIAN NURSING SCHOOL: \\ ITS RELATION WITH PROFESSIONAL IDENTITY (1947-1965)
}

\section{VESTUARIO DE LAS ALUMNAS EN UNA ESCUELA DE ENFERMERÍA BRASILEÑA: LAS RELACIONES CON LA IDENTIDAD PROFESIONAL} (1947-1965)

\author{
Regina Lucia Muniz de Almeida * \\ Pacita Geovana Gama de Sousa Aperibense ${ }^{* *}$ \\ Ângela Aparecida Peters Rodrigues ${ }^{* * *}$ \\ Mariângela Aparecida GonÇalvez de Figueiredo ${ }^{* * * x}$ \\ TÂNIA CRISTINA Franco SAnTos ${ }^{* * * * *}$ \\ Antonio José de Almeida Filho ${ }^{* * * * * *}$ \\ Maria Angélica de Almeida Peres ${ }^{* * * * * *}$
}

\section{RESUMO}

Objetivos: Descrever o vestuário/uniforme usado pelas alunas da Escola de Enfermagem Hermantina Beraldo (EEHB) e analisar sua relação com a construção da identidade profissional da enfermeira diplomada nessa escola de 1947-1965. Método: Estudo histórico-social. Foram utilizadas fontes escritas, iconográficas e orais de ex-alunas e ex-professoras da escola. Os autores que abordam a identidade profissional e o vestuário subsidiaram a análise dos dados. Resultados: Emergiu a categoria: Vestuário/uniforme na EEHB nos primeiros anos de seu funcionamento: papel na construção da identidade profissional (1947-1964). Tanto o uniforme hospitalar como o de saúde pública das alunas, tinham como principais características cores e acessórios semelhantes aos utilizados na escola padrão, a Escola de Enfermagem Anna Nery da Universidade Federal do Rio de Janeiro. Conclusões: $\mathrm{O}$ uniforme na EEHB acompanhava simbolicamente a imagem da enfermeira diplomada naquele período com diferenças que permitiam a construção de uma identidade institucional, social e profissional das enfermeiras formadas nesta escola.

Palavras chave: História da Enfermagem, escolas de enfermagem, vestuário, identificação social.

\footnotetext{
* Enfermeira. Mestre em Enfermagem pela Escola de Enfermagem Anna Nery/Universidade Federal do Rio de Janeiro (EEAN/UFRJ). Enfermeira do Hospital Universitário da Universidade Federal de Juiz de Fora (HU-UFJF). Professora da Faculdade de Ciências Médicas e da Saúde (SUPREMA, Juiz de Fora/MG). Brasil. E-mail: munizreg@gmail.com

${ }^{* *}$ Enfermeira. Doutora em Enfermagem pela EEAN/UFRJ. Presidente da Associação de Ex-alunos da EEAN/UFRJ. Membro do Núcleo de Pesquisa de História da Enfermagem Brasileira (Nuphebras). Brasil. E-mail: pacitageovana@yahoo.com.br

${ }^{* * *}$ Enfermeira. Mestre em Enfermagem pela EEAN/UFRJ. Professora da Faculdade de Ciências Médicas e da Saúde (SUPREMA) Juiz de Fora/MG. Membro do Nuphebras. Brasil. E-mail: angelaprodrigues@yahoo.com.br

${ }^{* * * *}$ Enfermeira. Doutora em Enfermagem pela EEAN/UFRJ. Enfermeira do HU-UFJF. Membro do Nuphebras. Brasil. E-mail: mary.hu@ig.com.br

${ }^{* * * * *}$ Enfermeira. Doutora em Enfermagem pela EEAN/UFRJ. Professora do Departamento de Enfermagem Fundamental da EEAN/UFRJ. Bolsista de Produtividade CNPq. Membro do Nuphebras. Brasil. E-mail: taniacristinafsc@gmail.com

${ }^{* *}$ Enfermeiro. Doutor em Enfermagem pela EEAN/UFRJ. Professor do Departamento de Enfermagem Fundamental da EEAN/UFRJ. Membro da 23a Diretoria Colegiada do Nuphebras. Brasil. E-mail: ajafilhos@gmail.com

${ }_{* * * * * * *}$ Enfermeira. Doutora em Enfermagem pela EEAN/UFRJ. Professora do Departamento de Enfermagem Fundamental da EEAN/UFRJ. Membro da 23a Diretoria Colegiada do Nuphebras. Brasil. E-mail: angelica.ufrj@uol.com.br
} 


\section{ABSTRACT}

Objectives: To describe the clothing/uniform worn by the students of the Hermantina Beraldo Nursing School (HBNS) and to analyze its relation to professional identity building in graduate nurses from this school in the period 1947-1965. Method: Historical and social study. Written, iconographic and oral sources of data were delivered by former students and former school teachers for this study. The data analysis was financed by the authors addressing the concepts of professional identity and uniforms in nursing schools. Results: We identified the following category: Clothing/uniforms in the first years of the HBNS: their role in professional identity building (1947-1964). The colors and accessories of both the hospital uniform and the uniform worn by students at public health care establishments remained similar to those worn at the sponsor school Anna Nery School of Nursing. Conclusions: The uniforms worn at the HBNS became a symbol for this school's graduates at that time, which led to the creation of an institutional, social and professional identity.

Key words: History of Nursing, schools nursing, clothing, social identification.

\section{RESUMEN}

Objetivos: Describir el vestuario/uniforme usado por los alumnos de la Escuela de Enfermería Hermantina Beraldo (EEHB) y analizar su relación con la construcción de la identidad profesional de la enfermera en esta escuela desde 1947 hasta 1965. Método: Estudio histórico y social. Se utilizaron fuentes escritas, iconográficas y orales de las ex alumnas y ex profesores de la escuela. El análisis de los datos fue subvencionado por los autores que abordaron los conceptos de identidad profesional y vestuario. Resultados: Emergió la categoría: vestuario/ uniforme en la EEHB en los primeros años de su funcionamiento: papel en la construcción de la identidad profesional (1947-1964). Tanto el uniforme del hospital como el de salud pública de los estudiantes tuvieron como principales característicos los colores y accesorios similares a los utilizados en la escuela patrón, la Escuela de Enfermería Anna Nery de la Universidade Federal do Rio de Janeiro. Conclusiones: El uniforme en EEHB acompañó simbólicamente la imagen de la Enfermera graduada en ese período, con diferencias que permitieron la construcción de una identidad institucional, social y profesional de los enfermeros formados en esta escuela.

Palabras clave: Historia de la Enfermería, escuelas de enfermería, vestuario, identificación social.

Fecha recepción: 21/07/15 Fecha aceptación: 03/10/16

\section{INTRODUÇÃO}

A Escola de Enfermagem Hermantina Beraldo (EEHB) foi criada como uma instituição estadual, pelo Decreto no 1.751 , de 03 de junho de 1946, e inaugurada em 8 de março de 1947. Foi à terceira escola de enfermagem do estado de Minas Gerais/Brasil, implantada com o objetivo de formar enfermeiras para atender à demanda de capacitação de profissionais para o exercício de atividades que exigiam novos conhecimentos e novas abor- dagens no tocante à assistência em saúde, na época, com enfoque no âmbito hospitalar (1, 2). A EEHB seguia os critérios de funcionamento legalmente estabelecidos no Brasil, dando continuidade ao processo de difusão da Enfermagem Moderna no país. Dentre as características das escolas de enfermagem criadas conforme o modelo oficial vigente estava à incorporação de emblemas e rituais, como elementos simbólicos constituintes da formação profissional (3). Assim ocorreu com as escolas de enfermagem criadas no estado de Minas Gerais que antecederam a 
EEHB, que foram a Escola de Enfermagem Carlos Chagas (EECC), criada em 1933, e a Escola de Enfermagem Hugo Werneck (EEHW), criada em 1942, ambas na cidade de Belo Horizonte (4-6).

Um importante emblema instituído nessas escolas foi o uniforme de alunas e de professoras/enfermeiras, que continha elementos representativos da imagem da enfermeira que se inseria na sociedade, dos quais se destaca o vestuário e seus elementos como a touca, $\mathrm{o}$ broche $\mathrm{e} o$ avental que funcionavam como um meio de comunicação e identificação, inclusive hierárquica sobre aquele grupo de alunas $(7,8)$.

A EEHB instituiu desde a sua primeira turma, uniformes para alunas e professoras, que guardavam semelhança com os uniformes utilizados em outras escolas do Brasil, de onde vieram suas primeiras dirigentes e professoras. Do início de seu funcionamento até o ano de 1964 as alunas não utilizavam uniforme em sala de aula. Usavam um uniforme nas atividades práticas hospitalares e outro nas atividades práticas de saúde pública (5).

$\mathrm{O}$ uniforme é uma vestimenta comum a toda uma categoria, confeccionado segundo um modelo oficial que pode variar na cor, forma e textura, de acordo com a época. $\mathrm{O}$ uniforme busca identificar as pessoas dentro de um ambiente institucional (escola, hospital, convento, entre outros) e confere autoridade, respeito, status perante a sociedade $(9,10)$. Contraditoriamente, distingue os uniformizados entre si através de modelos, cores, emblemas e brasões, que muitas vezes expressam posições hierárquicas que são, ao mesmo tempo, separatistas e discriminatórias $(11,12)$.

Assim, o objeto de estudo é o vestuário de alunas da EEHB de 1947 a 1965. O marco inicial é o ano de 1947 quando a escola inicia seu funcionamento e o marco final é o ano de 1965 quando o uniforme de aluna é modificado e a touca é retirada desse vestuário. Os objetivos foram: descrever o vestuário/uniforme usado pelas alunas da EEHB e analisar sua relação com a construção da identidade profissional da enfermeira diplomada nessa escola no período do estudo.

O estudo é relevante para a compreensão do significado do vestuário da enfermagem, ao longo dos anos, e da influência do mesmo na construção da identidade profissional da enfermeira diplomada na cidade de Juiz de Fora e no Brasil. A pesquisa contribui para a produção científica sobre o vestuário da enfermagem, rica na literatura internacional, porém ainda incipiente em nosso país, que vem ampliando a pesquisa sobre o tema.

\section{MÉTODO}

Estudo histórico-social, descritivo. Como base teórica utilizou-se o pensamento do sociólogo francês Claude Dubar, acerca da construção da identidade profissional em que apresenta a identidade sendo formada numa trajetória de vida, sempre num processo de construção/desconstrução e reconstrução (13). O estudo se vale também de obras que abordam a moda e o vestuário, com destaque para o sociólogo francês Roland Barthes, inaugurador da vertente que estuda a moda como signo de sociedade. $\mathrm{O}$ autor considera o vestuário uma linguagem abstrata, que carrega em si aspectos práticos e simbólicos que permitem comunicar informações sobre quem o está usando, sua época e influência. Utilizado como interface entre o corpo humano e o meio em que se vive (cultura, sociedade, economia), suas funções são múltiplas e suas origens são complexas, não podendo ser reduzido unicamente à sua funcionalidade $(14,15)$.

As fontes primárias incluíram documentos escritos, iconográficos e orais. Os documentos escritos pertencentes a Universidade Federal de Juiz de Fora, como: livros de registros, ata de formatura da primeira turma da EEHB e Registro Acadêmico; Ofícios sobre EEHB localizados na Gerência Regional de 
Saúde de Juiz de Fora (GRS-JF); Legislações e reportagens jornalísticas, publicadas no Jornal Diário Mercantil e Relatórios da Santa Casa de Misericórdia de Juiz de Fora (SCMJF).

As fotografias que contém o registro dos uniformes usados na EEHB no recorte temporal do estudo. As fotografias foram buscadas nos jornais da época e nos acervos pessoais das colaboradoras deste estudo. Além disso, o estudo contou com oito colaboradoras: duas ex-professoras e seis ex-alunas da EEHB, através da técnica da história oral temática, com um roteiro pré-estabelecido para cada colaborador, testemunharam os eventos relacionados ao objeto de estudo (16, 17). A participação na pesquisa respeitou os princípios éticos estipulados pela Resolução no 466/12 do Conselho Nacional de Saúde, aprovado no Comitê de Ética em Pesquisa da Escola de Enfermagem Anna Nery/Hospital Escola São Francisco de Assis (EEAN/HESFA), pelo parecer 168.815/ 2012.

As entrevistas, realizadas no segundo semestre de 2013, se deu nas residências ou local de trabalho das colaboradoras, de acordo com a disponibilidade e conveniência de cada uma. A média de duração das entrevistas foi de trinta minutos. A identificação das colaboradoras no texto se deu pela letra $\mathrm{C}$ seguida do número ordinal referente à ordem de realização da entrevista $(\mathrm{C} 1, \mathrm{C} 2 \ldots)$.

As fontes secundárias compreenderam artigos, livros, teses e dissertações referentes à história da enfermagem, em especial a história da EEHB, história do Brasil e também aquelas referente ao vestuário, em especial aos uniformes de enfermeiras, moda e identidade profissional.

As fontes foram analisadas utilizando-se o método indutivo que parte de uma postura crítica aos documentos, estabelecendo as relações com o contexto histórico social em que estavam inseridos. A análise dos dados e a discussão dos resultados apoiaram-se no referencial teórico do estudo.

\section{RESULTADOS}

\section{Vestuário e a construção da identidade da aluna da EEHB}

A primeira turma da EEHB, que tinha 8 alunas, começou suas atividades estudantis no mês de março de 1947. As aulas teóricas eram ministradas nas salas de aula localizadas na sede da escola. Para esta atividade não era exigido o uso de uniforme, conforme afirma a colaboradora C6 (2013):

Na sala de aula a gente não usava uniforme, era roupa comum.

Quanto às professoras da EEHB, estas usavam o uniforme de enfermeira diplomada, estipulado em sua escola de formação conforme relato:

Tinha sim. O [uniforme] das professoras era de linho branco, mas não era igual ao nosso. Tinha uma professora lá da Anna Nery [Escola de Enfermagem Anna Nery], Maria Helena Guedes. Ela usava um uniforme branco depois ela deu aulas de saúde pública também, usava o uniforme azul marinho $(C 1,2013)$.

Após o período de ensino básico teórico em sala de aula, as alunas eram encaminhadas para as enfermarias da Santa Casa de Misericórdia de Juiz de Fora (SCM-JF), campo prático da escola, onde eram desenvolvidos procedimentos de enfermagem, bem como o aprimoramento de atitudes profissionais desejáveis no cotidiano assistencial.

Neste momento, passavam a utilizar o uniforme instituído pela escola que foi assim descrito pelas colaboradoras:

O uniforme era um vestido inteiriço, de fustão branco, aberto na frente com dois botões, com bolso, de manga curta. Na manga tinha o sinal do ano que a pessoa estava cursando. Eram três 
sinais porque o primeiro ano já contava, sendo o comprimento abaixo do joelho (C2, 2013).
O uniforme da escola constava de um vestido de fustão branco tipo evasê [a saia]. O comprimento era bem abaixo do joelho. Meias brancas e sapato branco e um avental que cruzava atrás $(C 5,2013)$.

Figura 1. Uniforme hospitalar e avental das alunas da EEHB (1947-1965)
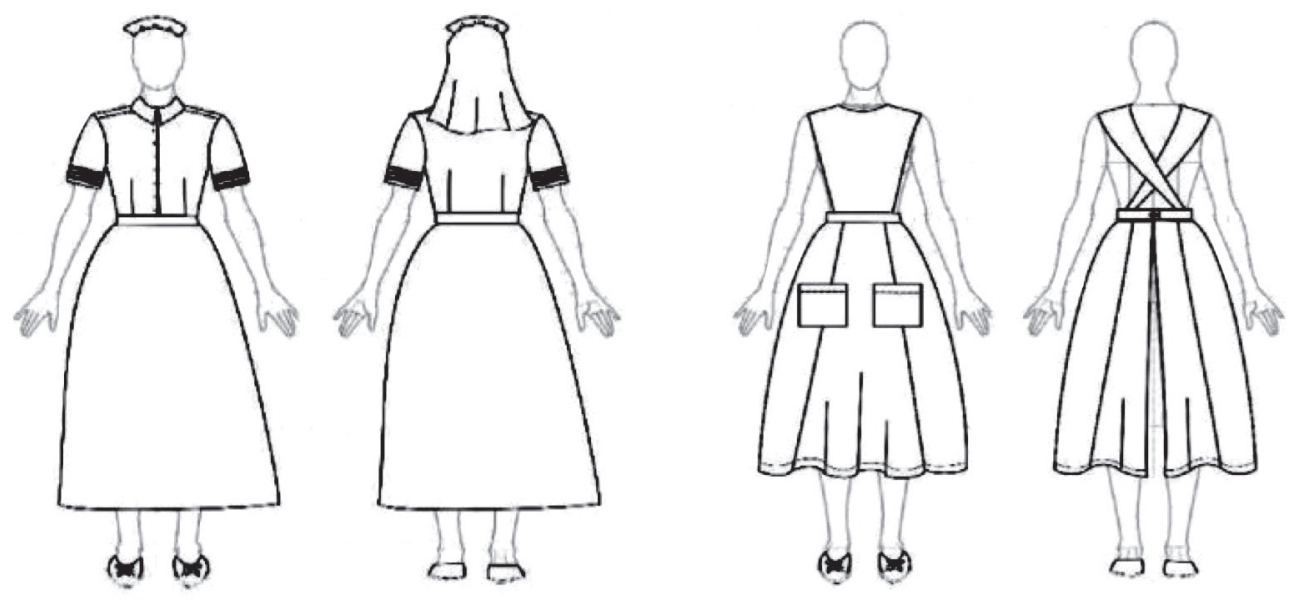

Fonte: Designer Aline Costa, 2013.

As divisas na manga do vestido da aluna eram um sinal de identidade e hierarquia. Indicavam além da instituição, o ano cursado o que diferenciava o uniforme da EEHB dos uniformes de outras instituições, a exemplo da EECC que, ao invés da divisa, tinha uma braçadeira com a Cruz de Malta na manga do vestido.

Os uniformes utilizados na EEHB estavam carregados de simbolismo e tradição em seus detalhes, tais como, a manga curta da blusa, a saia evasê do vestido, e o avental amarrado nas costas. Na cerimônia de formatura observou-se a diferença entre as toucas da diretora e da formanda. A diretora usava a touca de sua escola de formação (EECC) enquanto a aluna utilizava a touca de diplomada da EEHB, possibilitando uma distinção e identificação das enfermeiras na cidade de Juiz de Fora, por explicitar, através da linguagem não-verbal a escola de formação de cada uma em sinal de respeito e preservação da identidade das escolas. Do mesmo modo, a touca de aluna era uma importante marca de hierarquia e identidade no uniforme da EEHB. Assemelhava-se à touca utilizada pelas alunas do curso geral da EECC na década de 1940, ou ao uso do véu utilizado por religiosas, como na parte inferior da fotografia a seguir, na qual a touca em destaque é de aluna: 
Figura 2. Cerimônia de formatura na EEHB - 1957: juramento.

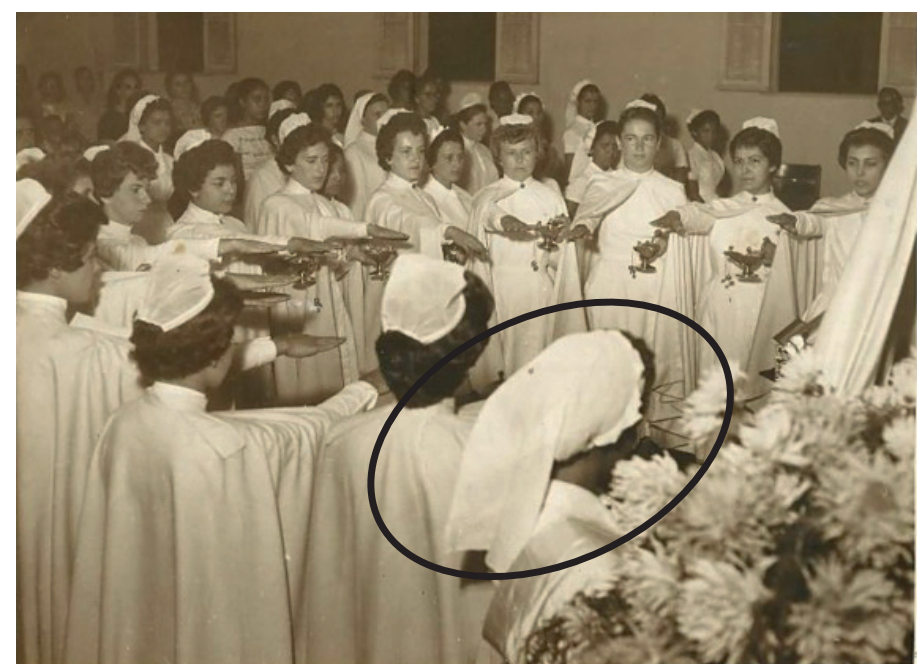

Acervo pessoal: Rachel Audebert Delage.

A touca era um acessório que compunha o uniforme utilizado pelas alunas durante as atividades práticas, estágios, nas solenidades da escola e em outras ocasiões formais em que se apresentavam enquanto grupo representante de uma instituição de ensino. Como símbolo da enfermagem, a touca também exigia como característica funcional, os cabelos presos em rede, numa denotação do zelo com a higiene.

É importante destacar que, até aquele momento, na cidade de Juiz de Fora não havia outras escolas para formação de enfermeiras. Há registros sobre possibilidade de retirada da touca na EECC, acessório que desagradava parte das alunas. A fala das ex-alunas da EEHB demonstrara a insatisfação quanto ao seu uso devido ao modelo, à dificuldade de cuidar e engomar o acessório e por assemelhá-las às religiosas:

A gente ria porque nós não gostávamos muito da touca, não! Parece que a gente estava com um "pegador de borboleta". Não gostávamos por causa da ponta comprida que caía sobre os ombros e também porque a gente ficava parecendo freira. $(C 1,2013)$.
A escola manteve características da vestimenta, inclusive o uso da touca no ambiente hospitalar, até o ano de 1965, perfazendo um período de 18 anos sem que fossem feitas alterações, entendido como fator de consolidação da identidade da enfermeira naquela instituição.

Para as atividades práticas de saúde pública, até meados de 1967, o uniforme das alunas da EEHB era composto por saia e blazer na cor azul marinho, blusa branca, meias da cor da pele e sapatos pretos, de acordo com a ilustração a seguir, feita a partir das descrições feitas pelas colaboradoras.

$\mathrm{Na}$ Figura 3 visualiza-se os detalhes da roupa: saia estilo envelope, mais ajustado ao corpo do que o uniforme utilizado nas práticas hospitalares. Na parte posterior da saia, da altura dos quadris até o joelho, havia uma abertura que possui duas dobras idênticas e viradas para dentro, como se fosse uma caixa. A prega macho permitia o alargamento da roda da saia acima dos joelhos e dava às alunas maior flexibilidade de movimentos para subir escadas e fazer caminhadas, atividades frequentes da enfermeira de saúde pública durantes as visitas domiciliares. 
Figura 3. Uniforme de saúde pública das alunas da EEHB (1947-1965).
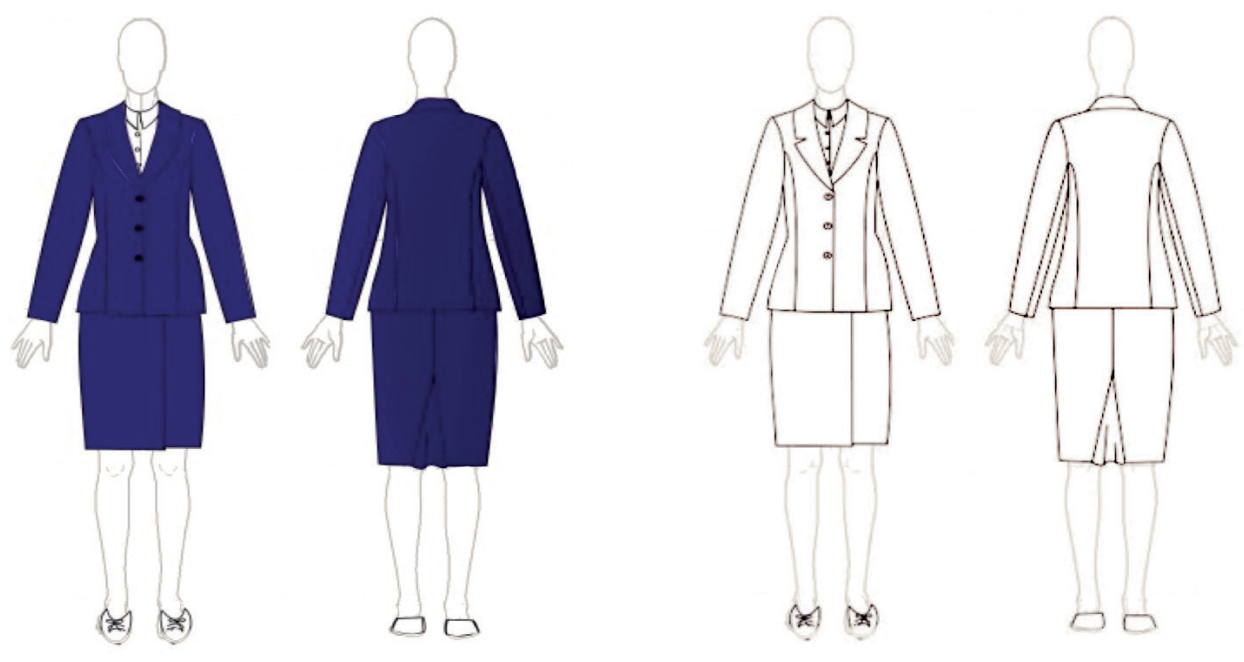

Fonte: Designer Aline Costa, 2014.

Sobre o uniforme na saúde pública, temse que a blusa era semelhante a uma camisa, com manga curta, gola esporte, fechada na frente por botões, sendo que a cor destes não foi especificada pelas colaboradoras. O blazer era azul marinho, gola tipo colarinho, com botões (as colaboradoras não souberam precisar quantos botões eram utilizados, nem a cor dos mesmos), meias de seda cor da pele, sapatos pretos, fechados e uma maleta na cor preta. Os cabelos deveriam ser mantidos alinhados, mas não se usava nenhum acessório na cabeça:

\section{[...] blusa branca, saia justa, azul marinho com} um machinho atrás ou uma abertura e um blazer também na cor azul marinho. Sapato abotinado, preto e meia cor da pele. Na cabeça não usávamos nada (C9, 2013).

Compondo o uniforme de saúde pública, em dias frios, as alunas utilizavam blusa de mangas compridas, não sendo exigido um modelo padrão, porém a cor tinha que ser branca como descrito pela colaboradora C9 (2013), aluna que ingressou no curso em 1965:
Tinha que ser blusa de lã branca. Podia vestir blusa de frio, mas branca! Fazia bastante frio naquela época.

O trato com os uniformes, incluindo seus acessórios era uma forma de se manter vivo o significado simbólico desse tipo de vestuário. A exigência de manter os uniformes sempre em boas condições, limpos e engomados levava a uma especial dedicação aos mesmos. As alunas da década de 1950 assim comentaram:

A gente lavava na escola. Era uma dificuldade. Ficava tudo amarelo. À noite me lembro de alguém passando a roupa (C3 2013).

Com o passar dos anos as alunas que moravam no internato, continuavam relatando as dificuldades no trato com os uniformes, $\mathrm{o}$ que se confirma no seguinte relato da aluna do ano de 1961:

Dava trabalho cuidar deste uniforme! Tinha que engomar! E quem podia ter mais de um ainda era mais fácil. Mas eu, por exemplo, só pude ter um! Então, todo final de semana a gen- 
te tinha que lavar e engomar direitinho! (C6, 2013).

\section{DISCUSSÃO E CONCLUSÃO}

No Brasil, nas primeiras décadas do século XX, ocorreu a implantação de uma nova identidade de enfermeira não religiosa, apesar da religiosidade presente nas primeiras líderes brasileiras da enfermagem (12).

Entre as décadas de 1940 e início de 1950, estudos apontam que o uniforme de Saúde Pública da EEAN era composto de saia azul marinho até a altura do joelho, modelo godê que permitia a liberação do movimento pelo número de franzidos e blusa branca mantida para fora da saia com o punho na altura da foça cubital. Um chapéu preto tipo cowboy, meias e sapatos pretos e a maleta para transporte do material eram os acessórios que completavam este uniforme da EEAN, o qual a professora manteve usando na EEHB (18-21). Embora não fosse exigido um uniforme nas aulas teóricas, não era qualquer roupa que a aluna poderia usar na escola. Seu vestuário estava restrito ao vestido, dentro dos padrões morais de vestuário da época, que exigia das mulheres o uso de roupas mais sóbrias e tecidos mais rústicos $(18,21-23)$.

Enquanto estrutura verbal, o vestuário escrito representa-se transformado em linguagem, em que as palavras carreiam juntamente com os traços indumentários já construídos, um sistema de significação revelada através do recurso da linguagem (14). Apesar de expressa em palavras, a roupa continua a preservar a neutralidade da descrição, entretanto ao associarem a formação da identidade das alunas da EEHB (22), as colaboradoras imprimem a elas sentido, significado, história (15). Cabe aqui destacar ainda, a importância do vestuário escrito no sentido de que "existem funções específicas da linguagem das quais a imagem não poderia dar conta independente de seu desenvolvimento na sociedade contemporânea" (14).

$\mathrm{O}$ vestuário é confeccionado com uma matéria prima que geralmente é o tecido, produzido para atender aos diferentes usos na sociedade. $\mathrm{O}$ uniforme é um tipo de vestuário constituído por peças que compõem o traje (saia, blusa, calça, vestido, capa) e por acessórios que servem para fixá-los ou complementá-los (chapéu, véu, broches, etc.). Confeccionado com suas formas e seu simbolismo ganha finalidades diversas e significação na sociedade (14).

Observa-se que as alunas ao usarem suas vestimentas particulares em sala de aula, também estavam sujeitas a uma limitação imposta pela escola. O grupo de alunas era em maioria constituído de jovens e adolescentes em processo de formação, fase em que um conjunto de atitudes como o hábito de vestir-se, comer, bem como o modo de agir; e práticas cotidianas passam a ser "incorporado pelo indivíduo para dar forma material à construção de uma identidade baseada na individualidade" (24). Este processo de socialização das alunas, através da incorporação de um "saber de base", assegurava em simultâneo 'a posse subjetiva de um eu e de um mundo', consolidando os papéis sociais que elas deveriam incutir em sua identidade profissional $(15,25)$.

As professoras ao usarem o uniforme correspondente à sua escola de formação tornavam-se uma referência identitária e mostrava para as alunas da EEHB o sentimento de pertença à categoria de Enfermeira Diplomada, dando exemplo de que deveriam usar o uniforme de sua escola depois de formadas. Nesse sentido, construía-se uma ética e uma estética, subjacente ao esforço de ensinar às alunas como deveriam se comportar como enfermeiras, ensinavam-se gestos, posturas, modos da identidade da enfermeira esperada. Sendo assim, a roupa que constitui o uniforme, não só cumpre um papel biológico de proteção, mas também sociológico e antropológico (18). O vestuário, no sentido da ves- 
timenta, desempenha papel importante na construção social da identidade. Todavia, essas identidades se reproduzem e se transformam pela própria dinâmica social, fazendo com que sua dimensão profissional adquira uma importância particular por também condicionar a construção das identidades sociais (13).

A cor branca instituída nos uniformes das enfermeiras hospitalares no Brasil, a partir da década de 1920, apresentou variações no transcorrer de sua trajetória histórica pelo país, mas foi preferencialmente usada nos uniformes de enfermeiras e demais profissionais na área da saúde, sendo-lhe atribuída referências à pureza, clareza, higiene, limpeza $\mathrm{e}$ paz $(26,27)$. Assim, traz um forte poder simbólico de higiene e saúde que, culturalmente, é esperado que seja usado pelos médicos, odontólogos, enfermeiros, por aqueles que tratam a pessoa doente $(26,28)$. Mas, o uso dessa cor nas roupas veio carregado de diferentes significados, de pureza à homogeneização e distinção de classe e status $(29,30)$.

As diferenças produzidas pelos acessórios presente no uniforme de alunas da EEHB eram a marca da identidade destas, embora aspectos semelhantes como o comprimento até os joelhos e a sobriedade fossem guardados por todos os outros modelos adotados pelas escolas de enfermagem da época, como a EECC e a EEAN. Não obstante, todos os uniformes demarcavam a hierarquia entre as alunas e entre estas e as diplomadas.

A touca, desde a implantação da enfermagem moderna no Brasil, foi um dos símbolos da enfermagem com um significado intimamente ligado aos valores religiosos como distinção, recato, sobriedade, bem como aos valores e compromissos exigidos para o exercício da profissão de enfermagem (7). O significado atribuído à touca "era o domínio de si mesma e a devoção à causa da Enfermagem" (3). Nesse sentido, "a touca das alunas sempre esteve impregnada de forte valor simbólico, uma vez que representava a mística da profissão, definida como valor essen- cial, e constituía simultaneamente estratégia de igualdade e distinção do grupo" (3).

Se por um lado era também uma forma de minimizar os atributos femininos presentes nos cabelos das mulheres, que concentram vários significados: "os cabelos são a mulher, a carne, a feminilidade, a tentação, a sedução, o pecado" (30).

O cuidado com os uniformes e os acessórios, entre eles a touca e os sapatos, faziam parte do cotidiano das alunas de outras escolas de enfermagem anteriores a EEHB. Citamos a EEAN e a EECC, escolas que contribuíram para reprodução de comportamentos como zelo e amor ao uniforme, que deveria ser usado não somente como uma vestimenta que cobria o corpo, mas impregnado de uma simbologia que gradativamente foi sendo incorporada pelas alunas de enfermagem e enfermeiras diplomadas $(7,22)$.

Ao analisar as fontes orais é possível afirmar que as alunas, além das atividades de estudos que comprometia boa parte do dia, também tinham a responsabilidade de cuidar dos uniformes e mantê-los limpos e engomados. Atividades que também demandavam tempo e zelo, concorrendo para a construção da identidade profissional, onde se estabelece a responsabilidade com a imagem também representada pela condição do vestuário. Através desse processo de cuidar do uniforme as estudantes experimentavam tipificações identitárias em um ambiente no qual relações simbólicas e materiais se efetivaram concretamente.

A trajetória empreendida pela EEHB levou a escola a ser reconhecida e respeitada na sociedade onde existia. Ocupou espaços tanto no meio acadêmico quanto na área da saúde, especialmente na SCM-JF, que merece ser destacada pelo interrelacionamento que estabeleceu com a Escola ao oferecer espaço para a realização de atividades acadêmicas e para o exercício profissional, com a contratação de enfermeiras diplomadas pela EEHB (5). Deste modo temos que "o espaço de reconhecimento das identidades é indissoci- 
ável dos espaços de legitimação dos saberes e competências associados às identidades. A transação objetiva entre os indivíduos e as instituições é essencialmente a que se organiza em torno do reconhecimento" (13).

Os diversos espaços sociais vivenciados pelas alunas e professoras da EEHB no cotidiano da vida escolar, na sociedade de Juiz de Fora e nas outras cidades que compartilharam o processo de formação acadêmica, possibilitaram a concepção de uma identidade profissional e social, concretizada ao longo dos anos, permitindo o reconhecimento da enfermeira como profissional qualificada pertencente à equipe de saúde.

$\mathrm{O}$ desenvolvimento desta pesquisa possibilitou descrever o uniforme enquanto componente significativo para a formação e afirmação da identidade do grupo de enfermeiras diplomadas pela EEHB no período de 1947 a 1965. Permitiu também, descrever, através dele, todo um contexto social e cultura reinante à época na cidade de Juiz de Fora.

Ao buscarmos descrever os uniformes da EEHB foi possível verificar com este estudo, o quanto esse tipo de vestuário é significativo para quem o usa e a sua representação simbólica, que permite a lembrança de todo o contexto que envolve o seu uso, seja referente ao cotidiano institucional ou aos aspectos políticos, sociais e culturais da região.

Os uniformes de alunas da EEHB, como fragmento de um universo chamado "vestuário", contribuíram para a identificação de uma categoria profissional em formação, transmitindo tanto uma imagem quanto uma linguagem emblemática para alunas, professores e demais profissionais que compartilharam do mesmo momento histórico e social, uma vez que transmitiam novos conceitos da ciência, da técnica e de um ideal de assistência à saúde a ser prestado à população.

As fontes do estudo, bem como o referencial teórico, permitiram descrever os primeiros uniformes (hospitalar e de saúde pública) utilizados pelas alunas da institui- ção, bem como evidenciar que os mesmos se assemelhavam aos utilizados pelas escolas de referência na época, a saber: EEAN e EECC, o que representa a reprodução do modelo vigente á época.

\section{REFERÊNCIAS}

1. Figueiredo MAG, Batista SS. Curso de Enfermagem da Universidade Federal de Juiz de Fora: 1977-1979. Rev Bras Enferm. 2009; 62(4): 512-17.

2. Jesus MC, Santos SMR, Figueiredo MAG, Gava GF, Pereira FO. Primeira década do curso de enfermagem na Universidade Federal de Juiz de Fora: 1979-1989. Esc Anna Nery. 2012; 16(2): 255-262.

3. Santos TCF. Significado dos Emblemas e Rituais na Formação da Identidade da Enfermeira Brasileira: uma reflexão após oitenta anos. Esc Anna Nery. 2004; 8(1): 81-86.

4. Santos FBO, Marques RC. Egressas da Escola de Enfermagem Carlos Chagas: campos de atuação. 1936-1948. Esc Anna Nery. 2015; 19(2): 363-368.

5. Araújo MA, Nascimento ES, Caldeira VP. Criação e implantação da Escola de Enfermagem Hermantina Beraldo gestão Celina Viegas. REME. 2004; 8(3): 358363.

6. Toledo JR, Santos TCF, Araújo MA, Almeida Filho AJ. Emblemas e rituais: reconstruindo a história da Escola de Enfermagem Hermantina Beraldo. Esc Anna Nery. 2008; 12(2): 243-250.

7. Peres MAA, Barreira IA. Significado dos uniformes de enfermeira nos primórdios da enfermagem moderna. Esc Anna Nery. 2003; 7(1): 25-38.

8. Peres MAA, Padilha MIS. Uniforme como signo de uma nova identidade de Enfermeira no Brasil (1923-1931). Esc Anna Nery. 2014; 18(1): 112-121.

9. Farias RCP. Transubstanciação simbó- 
lica do uniforme de trabalho em signo de prestígio. An. mus. paul. 2010; 18(2): 263-284.

10. Román CAL. El uniforme y su influencia en la imagem social. Rev Cubana Enfermer [Internet]. 2006 Ene-Mar [citado 18 set 2016]; 22(1): 1-15. Disponível em: http://www.bvs.sld.cu/revistas/enf/ vol22_1_06/enf06106.htm

11. Schemes C, Araújo DC, Thön IH. "Nem tão distantes": relações entre o uniforme escolar e a moda europeia - um estudo de caso. Fênix - Revista de História e Estudos Culturais. 2013; 10(2): 01-17.

12. Peres MAA, Padilha MICS. Uniforme como signo de uma nova identidade de enfermeira no Brasil (1923-1931). Esc Anna Nery 2014; 18(1): 112-121.

13. Dubar C. A Socialização: Construção das Identidades Sociais e Profissionais. São Paulo: Ed: WMF. Martins Fontes; 2005. p. 155.

14. Barthes R. Sistema da Moda. Trad. Ivone Castilho Benedetti. São Paulo: WMF Martins Fontes; 2009. 476 p.

15. Barthes R. Imagem e Moda. Trad. Ivone Benedetti. São Paulo: Martins Fontes; 2005. $380 \mathrm{p}$.

16. Meihy JCSB, Holanda F. História Oral: como fazer, como pensar. 2da ed. São Paulo: Contexto; 2013. 175 p.

17. Macêdo MLAF, Costa MCMDR, Lima SP, Padilha MI, Borenstein MS. História oral temática na pesquisa em enfermagem: estudo bibliométrico. Cogitare Enferm. 2014; 19(2): 384-91.

18. Nacif MCV. O vestuário como princípio de leitura do mundo [Internet]. XXIV Simpósio Nacional de História; 15-20 de junho de 2007; São Leopoldo, RS: ANPUH Associação Nacional de História, Unisinos; [citado 14 jun 2012]. Disponível em: http://snh2007.anpuh.org/ site/anaiscomplementares\#M

19. Almeida RC, Aperibense PGGS, Santos TCF, Peres MAA. Uniforme de Saúde Pública na Escola Anna Nery no período de
1931 a 1949 [Internet]. Anais da 19a Jornada Nacional de História da Enfermagem; 18 de maio de 2016; Rio de Janeiro: Departamento de Enfermagem Fundamental-Escola de Enfermagem Anna Nery; [citado 02 jun 2016]. Disponível em: http://www.pesquisandoenfermagem.com.br/2016-23/wp-content/uploads/2016/05/anais2016_pesquisando.pdf

20. Aperibense PGGS. Uniformes e suas relações com a identidade profissional do enfermeiro formado pela Escola de Enfermagem Anna Nery da Universidade Federal do Rio de Janeiro (1969-1985). [Tese doutorado]. Rio de Janeiro: UFRJ/ EEAN; 2016. 220 p.

21. Leite AS, Velloso MD. Desenho técnico de roupa feminina. Rio de Janeiro: Ed. Senac Nacional; 2007. 157 p.

22. Deslandes AKM, Aguiar S, Neto M, Porto FR. A imagem do cuidado prestado pelas enfermeiras de saúde pública veiculada na Revista da Semana (1929). Rev Lat Am Enfermagem. 2013; 21(1): 412-418.

23. Nascimento ES, Santos GF, Caldeira VP. Criação, quotidiano e trajetória da escola de Enfermagem da UFMG: um mergulho no passado. Belo Horizonte: Ed. Segrac; 1999. $218 \mathrm{p}$.

24. Zimmermann M. Diálogos entre moda e rua: Teddy Boys: de subcultura a cultura de massa. Ponto Urbe [Internet]. 2012 [citado 02 abr 2014]; 11. Disponível em: https://pontourbe.revues.org/1113\#quotation

25. Hall S. Quem precisa da identidade? En: Silva, TT (org). Identidade e diferença: a perspectiva dos estudos culturais. $10^{\mathrm{a}} \mathrm{ed}$. Petrópolis, RJ: Vozes; 2011. 133 p.

26. Farina M, Perez C, Basto D. A psicodinâmica das cores em comunicação. $6^{a}$ ed. Ed: Edgard Blücher Ltda, 2011.192 p.

27. Beck CLC, Lisboa Filho FF, Lisboa MGP, Lisboa RL. A Linguagem Sígnica das Cores na Ressignificação (Humanização) de Ambientes Hospitalares [Internet]. XXX Congresso Brasileiro de Ciências da Co- 
municação; 29 de agosto a 2 de setembro de 2007; Santos, SP: Intercom - Sociedade Brasileira de Estudos Interdisciplinares da Comunicação; [citado 7 maio 2013]. 11 p. Disponível em: http://www.iar.unicamp.br/lab/luz/ld/Arquitetural/Pesquisa/a_linguagem_signica_das_cores_na_ resiginificacao_de_ambientes_hospitalares.pdf
28. Guimarães L. A Cor como informação: a construção biofísica, lingüística e cultural da simbologia das cores. $3^{a}$ ed. rev. São Paulo: Editora Annablume; 2004. 160 p.

29. Martins EF, Martins CJ. O uniforme enquanto objeto sígnico na área da saúde. Verso e Reverso. 2011; XXV(59): 100-108.

30. Perrot M. Minha História das mulheres. São Paulo: Contexto; 2007. 190 p. 